(2) Open Access Full Text Article

ORIGINALRESEARCH

\title{
Assessment of Staffing and Service Provision in the Post-Anesthesia Care Unit of Hospitals Found in Amhara Regional State, 2020
}

\section{Basazinew Chekol (D) \\ Denberu Eshetie (iD) \\ Netsanet Temesgen (ID}

Department of Anesthesia, College of Health Sciences, Debre Tabor University, Debre Tabor, Ethiopia
Correspondence: Basazinew Chekol Department of Anesthesia, College of Health Sciences, Debre Tabor University, PO.Box: 272, Debre Tabor, Ethiopia Tel +251921577I3I

Email basechek06@gmail.com
Background: Post-anesthesia recovery is a continuous process which is considered to be complete after the patient returns to their preoperative physiological state. Although all patients who have had an operation under anesthesia are in a potentially unstable physiological state, most patients recover safely without significant problems due to better and immediate post-anesthesia care. Therefore, this study aimed to assess the staffing and service provision in the post-anesthesia care unit.

Methods: A multicenter, institution-based cross-sectional study was conducted in postanesthesia care units from November 28 to December 31, 2020. The data were collected using a questionnaire prepared from standards and guidelines of the American Society of Anesthesiologists, the American Association of Nurse Anesthetists, and the Royal College of Anesthetists by direct observation.

Results: Ten hospitals found in Amhara regional state were examined for their staffing of and service provision in their post-anesthesia care units. The total ratio of nurses assigned in post-anesthesia care units to post-anesthesia care unit beds was around 1:3, with a minimum and a maximum ratio of 1:8 and 1:2, respectively. The average number of patients admitted in post-anesthesia care units per week was 98 . Eighty percent of the hospitals' post-anesthesia care units had no policy or caregivers for cardiac arrest management.

Conclusions and Recommendations: Standards, policies, and guidelines are not well prepared and posted so as to be visible to every caregiver. The majority of the hospitals have staff without special training for the management of possible complications in the postanesthesia care unit. Generally, hospitals need to ensure standardized patient care in the postanesthesia care unit for better and safer patient outcomes.

Keywords: post-anesthesia care, recovery, patient care, Ethiopia

\section{Introduction}

A post-anesthesia care unit (PACU)/recovery room (RR) is a vital part of hospitals which is normally attached to operating rooms, designed to provide care for patients recovering from anesthesia. The most frequent disturbances during the immediate postoperative period in PACU are acute pain, nausea and vomiting, delirium, shivering, dry mouth, and hunger. Postoperative care in early recovery should involve airway management and oxygen therapy, vital signs monitoring, postoperative pain management, postoperative nausea and vomiting treatment, treating postanesthesia shivering, and monitoring surgical sites for complications such as bleeding, discharge, swelling, hematoma, wound healing, and infection. ${ }^{1-3}$ 
Recovery from anesthesia is a hazardous process and patients require a high standard of care until recovery is complete. Many problems associated with anesthesia and surgery may occur in the immediate postoperative period, and it is essential that appropriate care by trained and experienced personnel should be continued in an appropriately equipped location during this time..$^{4-7}$

The PACU is a dynamic and acute clinical area where the number of patients and acuity may fluctuate rapidly due to different factors which are often difficult to control, for example delayed discharge and change in theatre lists. Standards for the staff-to-patient allocation and numbers and skill mix are appropriate to ensure the safety of all patients throughout their stay. ${ }^{8}$

PACU staffing is a problem for managers as they seek to overcome obstacles that may affect the constant onward flow of patients back to the wards. ${ }^{9}$ The PACU is a busy working area in which nurses may communicate with patients, family members, and a large team of perioperative professionals. ${ }^{10-12}$ The staffing plan guides identifying, analyzing, and training the human power that is needed to support institutional activities. This plan is also a living document that aids in the continuous evaluation of structures, positions, functions, staffing needs, professional training, and effective communication throughout the institution. ${ }^{13,14}$

According to the Association of Anesthetists of Great Britain and Ireland (AAGBI) recommendations, the PACU must have sufficient number of trained staffs throughout all operating hours, and it must be open for 24 hours for emergency surgical services. There should be a minimum of two caregivers for a single patient in the PACU.9,15,16

Patients unable to maintain their airways must be nursed continuously on a one-to-one basis as routine practice, even in peak periods. Cardiovascular and respiratory monitoring should be applied and clinical conditions should be observed until the patient has fully recovered from anesthesia. Since there may be different complications during an emergency state, appropriate monitoring and care are important for the safe outcome of patients in the immediate postoperative period. ${ }^{8,9,17,18}$

PACU patient care is one of critical health care providers' main concerns and urgently needs to be standardized. ${ }^{19,20}$ Staffing and service provision are quite different across different setups and there is a gap in real patient care according to our day-to-day personal observations in these study areas. Therefore the primary aim of this cross-sectional descriptive study was to assess the staffing and service provision of
PACUs in secondary- and tertiary-level government-run hospitals in the Amhara regional health bureau.

\section{Methods}

\section{Study Area, Period and Design}

The study was conducted in secondary- and tertiary-level government-run hospitals in Amhara regional health bureau, which is one of the regional states in Ethiopia. A total of ten hospitals (Debre Tabor, University of Gondar, Felege Hiwot, Tibebe Ghion, Debre Berhan, Dessie, Woldia, Finote Selam, Debre Markos, and Injibara General Hospital) participated in this study. A multi-center, descriptive, cross-sectional study was conducted on staffing of and service provision in PACUs in December 2020.

\section{Sample Size and Sampling Technique}

All government-run secondary and tertiary-level hospitals found in Amhara regional state were surveyed on staffing of and service provision in PACUs that provide postoperative patient care.

\section{Data Collection Tool and Technique}

The data collection tool was prepared based on the PACU standards of the American Society of Anesthesiologists (ASA), American Association of Nurse Anesthetists (AANA), Royal College of Anesthetists (RCoA), and Association of Anesthetists of Great Britain and Ireland (AAGBI). ${ }^{19-23}$ The tool was prepared according to the subheadings of Demography related to the hospitals, staffingrelated standards, logistics required for PACU services, and Service provision standards. This tool was used to collect data from anesthetists working in each hospital.

\section{Data Quality Assurance}

To ensure the quality of data, training was given to data collectors. The collected data was checked daily, irrespective of whether or not the questionnaires were properly completed following the prepared format.

\section{Data Analysis and Process}

After checking the completeness of the data collected, it was entered into SPSS version 20 software. A descriptive analysis was done using frequencies and percentages, which were summarized and interpreted in the form of text and tables. 


\section{Ethical Consideration}

Ethical approval and permission to collect data were obtained from the Debre Tabor University's College of Health Sciences' ethical approval committee. A formal letter of cooperation and permission was obtained from the Amhara regional health bureau. Also, permission to collect data was gained from each hospital's administration on the basis of the permission letter granted by the Amhara regional health bureau. Verbal and written informed consent was obtained from the respective PACU coordinators of each hospital.

\section{Results}

The data was collected from ten secondary and tertiarylevel government-run hospitals. In these hospitals, the number of operating tables and PACU beds ranged from 3-12 and 4-24, respectively. The total ratio of nurses assigned to the PACU to PACU beds in these hospitals was around $1: 3$, with a minimum and a maximum ratio of $1: 8$ and $1: 2$, respectively. The minimum, maximum, and average number of patients admitted in the PACU per week was 30, 201, and 98, respectively. The mean duration of patient stay in the PACU was $3.6 \pm 1.8 \mathrm{hrs}$. Anesthetists were assigned as the person responsible for patient care and other possible activities in the PACU in only one hospital.

\section{Staffing of PACUs}

The majority of hospitals have nurse professionals in the PACU without appropriate, specialist training. Patient transfer to PACU is the responsibility of the anesthetist in all hospitals. In two hospitals, the anesthetist always left the patient in the PACU without appropriate handover to the responsible persons (Table 1).

Table I Staffing of PACU in Secondary- and Tertiary-Level Hospitals in Amhara Regional State, 2020

\begin{tabular}{|c|c|c|}
\hline Standards/Activities & Categories & $\begin{array}{l}\text { Frequency, } \\
\text { n (\%) }\end{array}$ \\
\hline \multirow[t]{2}{*}{ Do staff in the PACU get appropriate training regarding PACU patient care? } & Yes & I (I0\%) \\
\hline & No & $9(90 \%)$ \\
\hline \multirow[t]{3}{*}{ Who is the person responsible for transporting patients from the operating room to the PACU? } & Physicians & 0 \\
\hline & Anesthetist & $10(100 \%)$ \\
\hline & Nurses & 0 \\
\hline \multirow{3}{*}{$\begin{array}{l}\text { Does a member of the anesthesia care team remain in the PACU until the PACU nurse accepts } \\
\text { responsibility for the nursing care of the patient? }\end{array}$} & Yes, always & $7(70)$ \\
\hline & Yes, sometimes & $\mathrm{I}(10)$ \\
\hline & No & $2(20)$ \\
\hline \multirow[t]{2}{*}{ Who is responsible for the general medical supervision and coordination of patient care in the PACU? } & Physicians & $6(60)$ \\
\hline & Nurses & $4(40)$ \\
\hline \multirow[t]{3}{*}{ Who is responsible for the discharge of the patient from the PACU? } & Physicians & $2(20)$ \\
\hline & Anesthetist & $\mathrm{I}(10)$ \\
\hline & Nurses & $7(70)$ \\
\hline \multirow[t]{3}{*}{ Who is responsible for approving the discharge criteria from PACU? } & Physician & $5(50)$ \\
\hline & Anesthetist & $\mathrm{I}(10)$ \\
\hline & Nurses & $4(40)$ \\
\hline \multirow[t]{2}{*}{ In the absence of the person responsible for discharge, what might be appropriate patient management? } & $\begin{array}{l}\text { Wait for the } \\
\text { responsible body }\end{array}$ & $3(30)$ \\
\hline & $\begin{array}{l}\text { Discharge with the } \\
\text { existing staff }\end{array}$ & $7(70)$ \\
\hline \multirow[t]{3}{*}{ Who is responsible for the coordination of the PACU? } & OR coordinator & $5(50)$ \\
\hline & PACU coordinator & $4(40)$ \\
\hline & Ward coordinator & I (I0) \\
\hline
\end{tabular}

Abbreviations: PACU, post-anesthesia care unit; OR, operating room. 


\section{Allocation of Equipment and Necessary Materials in the PACU}

Nine hospitals $(90 \%)$ have PACUs near to the operating room to receive patients following surgery. An appropriate PACU scoring system was present for each patient on admission, at appropriate intervals before discharge, and at the time of discharge in four hospitals (40\%). Eight hospitals (80\%) had no policy to assure the availability of caregivers capable of managing complications and providing CPR in the PACU (Table 2).

\section{Provision of services}

Only two hospitals prepare and utilize policies and procedures that help to govern patient care in the PACU. In these hospitals, the physicians and anesthetists are responsible for reviewing and approving such policies and procedures (Table 3 ).

\section{Discussion}

The PACU is an area where skilled health professionals deliver appropriate care to the patient in the immediate postoperative phase. The aim of patient care in the PACU is to ease the transition back to the ward without complications. The care is intended for the patients' safety until they become fully awake and able to resume their daily lives. ${ }^{24}$

The PACU is a dynamic and acute clinical area where a patient's condition may fluctuate rapidly due to different, and challenging, factors like delayed discharge and change in theatre lists. Standards to ensure staff-to-patient allocation, and numbers and skill mix are appropriate to ensure the safety of all patients throughout their stay. ${ }^{8,25}$ Allocation of staff and other resources is mandatory to deliver quality care in the PACU. Assessing staffing levels and even service provision according to appropriate logistic allocations in the PACU is helpful to achieve better patient care.

Post-anesthesia recovery is a continuous process until the patient returns to their preoperative physiological state.

Table 2 Availability and Utilization of Appropriate Equipment and Materials in the PACU of Secondary-and Tertiary-Level Hospitals in Amhara Regional State

\begin{tabular}{|c|c|c|}
\hline Standards/Activities & Response & $\begin{array}{l}\text { Frequency, } \\
\text { n (\%) }\end{array}$ \\
\hline Is a PACU available nearby to receive patients for post-anesthesia care? & $\begin{array}{l}\text { Yes, near to } \\
\text { the OR } \\
\text { No }\end{array}$ & $\begin{array}{l}9(90) \\
I(10)\end{array}$ \\
\hline $\begin{array}{l}\text { Does an appropriate PACU scoring system exist for each patient on admission, at appropriate intervals before } \\
\text { discharge, and at the time of discharge? }\end{array}$ & $\begin{array}{l}\text { Yes } \\
\text { No }\end{array}$ & $\begin{array}{l}4(40) \\
6(60)\end{array}$ \\
\hline $\begin{array}{l}\text { Is there a policy to assure the availability of caregivers capable of managing complications and providing CPR in } \\
\text { the PACU? }\end{array}$ & $\begin{array}{l}\text { Yes } \\
\text { No }\end{array}$ & $\begin{array}{l}2(20) \\
8(80)\end{array}$ \\
\hline Are oxygen and suction present in the PACU on every recovery day? & $\begin{array}{l}\text { Yes } \\
\text { No }\end{array}$ & $\begin{array}{l}8(80) \\
2(20)\end{array}$ \\
\hline $\begin{array}{l}\text { Is an audible and visible emergency call system in place, checked regularly to maintain its functionality, and } \\
\text { understood by all staff? }\end{array}$ & $\begin{array}{l}\text { Yes } \\
\text { No }\end{array}$ & $\begin{array}{l}4(40) \\
6(60)\end{array}$ \\
\hline $\begin{array}{l}\text { Are the drugs, fluids, and equipment required for resuscitation and the management of postoperative } \\
\text { complications available and maintained regularly? }\end{array}$ & $\begin{array}{l}\text { Yes } \\
\text { No }\end{array}$ & $\begin{array}{l}4(40) \\
6(60)\end{array}$ \\
\hline $\begin{array}{l}\text { Is there a system for ordering, storing, recording, and auditing of controlled drugs in all postoperative areas in } \\
\text { which they are used? }\end{array}$ & $\begin{array}{l}\text { Yes } \\
\text { No }\end{array}$ & $\begin{array}{l}5(50) \\
5(50)\end{array}$ \\
\hline Is there a pain assessment tool posted and used in the PACU? & $\begin{array}{l}\text { Yes } \\
\text { No }\end{array}$ & $\begin{array}{l}2(20) \\
8(80)\end{array}$ \\
\hline Are emergency management guidelines posted in the PACU? & $\begin{array}{l}\text { Yes } \\
\text { No }\end{array}$ & $\begin{array}{l}2(20) \\
8(80)\end{array}$ \\
\hline
\end{tabular}

Abbreviations: PACU, post-anesthesia care unit; OR, operating room; CPR, cardiopulmonary resuscitation. 
Table 3 Service Provisions and Related Activities in the PACU of Secondary- and Tertiary-level Hospitals in Amhara Regional State

\begin{tabular}{|c|c|c|}
\hline Standards/Activities & Response & $\begin{array}{l}\text { Frequency, } \\
\text { n (\%) }\end{array}$ \\
\hline Are all aspects of care in the PACU governed by policies and procedures? & $\begin{array}{l}\text { Yes } \\
\text { No }\end{array}$ & $\begin{array}{l}2(20) \\
8(80)\end{array}$ \\
\hline If "yes", who is the person responsible for reviewing and approving the standards and policies? & $\begin{array}{l}\text { Physicians } \\
\text { Anesthetist } \\
\text { Nurse }\end{array}$ & $\begin{array}{l}\mathrm{I}(50) \\
\mathrm{I}(50)\end{array}$ \\
\hline $\begin{array}{l}\text { Do all patients who have received general anesthesia, regional anesthesia, or monitored sedation anesthesia, } \\
\text { receive appropriate care management in the PACU? }\end{array}$ & $\begin{array}{l}\text { Yes, always } \\
\text { Yes, sometimes } \\
\text { No }\end{array}$ & $\begin{array}{l}7(70) \\
2(20) \\
1(10)\end{array}$ \\
\hline Are patients appropriately monitored during transportation from the operating room to the PACU? & $\begin{array}{l}\text { Yes, always } \\
\text { Yes, sometimes } \\
\text { No }\end{array}$ & $\begin{array}{l}4(40) \\
4(40) \\
2(20)\end{array}$ \\
\hline Are patients re-evaluated upon arrival in the PACU? & $\begin{array}{l}\text { Yes, always } \\
\text { Yes, sometimes } \\
\text { No }\end{array}$ & $\begin{array}{l}6(60) \\
3(40) \\
1(10)\end{array}$ \\
\hline $\begin{array}{l}\text { Does the anesthetist give a verbal report to the PACU nurses during handover regarding the status of the } \\
\text { patient? }\end{array}$ & $\begin{array}{l}\text { Yes, always } \\
\text { Yes, sometimes }\end{array}$ & $\begin{array}{l}8(80) \\
2(20)\end{array}$ \\
\hline Is the patient's status on arrival in the PACU documented? & $\begin{array}{l}\text { Yes, always } \\
\text { Yes, sometimes }\end{array}$ & $\begin{array}{l}8(80) \\
2(20)\end{array}$ \\
\hline $\begin{array}{l}\text { Is information concerning the preoperative condition and surgical/anesthetic course of the patient transferred } \\
\text { to the PACU nurse? }\end{array}$ & $\begin{array}{l}\text { Yes, always } \\
\text { Yes, sometimes } \\
\text { No }\end{array}$ & $\begin{array}{l}6(60) \\
3(30) \\
1(10)\end{array}$ \\
\hline $\begin{array}{l}\text { Is the patient observed and monitored by methods appropriate to their medical condition by paying particular } \\
\text { attention to oxygenation, ventilation, circulation, level of consciousness, and temperature? } \\
\text { Are there careful records including instructions, patient observations, and drug administration? }\end{array}$ & $\begin{array}{l}\text { Yes, always } \\
\text { Yes, sometimes } \\
\text { Yes, always } \\
\text { Yes, sometimes }\end{array}$ & $\begin{array}{l}6(60) \\
4(40) \\
8(80) \\
2(20)\end{array}$ \\
\hline Does the patient transfer from the PACU after fulfilling the discharge criteria? & $\begin{array}{l}\text { Yes, always } \\
\text { Yes, sometimes } \\
\text { No }\end{array}$ & $\begin{array}{l}6(60) \\
2(20) \\
2(20)\end{array}$ \\
\hline
\end{tabular}

Abbreviations: PACU, post-anesthesia care unit; OR, operating room.

Although all patients who have had an operation under anesthesia are in a potentially unstable physiologic state, most patients recover safely without significant problems due to better and immediate post-anesthesia care..$^{25,26}$

According to various guidelines and standards, PACUs should be staffed by specially trained personnel, able to care for patients who receive all types of anesthesia. Also, the ratio of nurses to patients in the PACU should be $1: 2 .{ }^{19,20,27}$ But in the study area, the ratio of nurses to bed numbers in the PACUs ranged from $1: 2$ to $1: 8$. Only one institution (10\%) had nurses who had received specialist training in PACU patient care.
Similar to the practices outlined in existing standards, patient transportation from operating room to PACU in all institutions in the study area was the responsibility of anesthesia professionals, with around $80 \%$ of hospitals ensuring appropriate monitoring during transportation.

In the present study, policies to govern overall patient care were not formulated and well-practiced. From the possible policies and guidelines, only two institutions $(20 \%)$ had policies to ensure that emergency caregivers are capable of managing possible complications in the PACU, providing appropriate $\mathrm{CPR}$, using pain assessment tools, and following emergency 
management guidelines. But, according to different guidelines, every PACU should have policies and guidelines in place, which should incorporate guidelines for monitoring, equipment and drugs, PACU staffing, transfer and handover of care, patient management in the PACU, discharge of patients from the PACU, and audit and quality control in the PACU. ${ }^{28}$

Patient readiness for discharge from the PACU needs to be addressed using a simple, clear, reproducible policy that meets national standards of medical and anesthesia care. Appropriate discharge criteria need to address: vital signs, ambulation, mental status, pain and nausea/vomiting, surgical site bleeding, and fluid intake/output. ${ }^{29-31}$ In our study, eight hospitals $(80 \%)$ use discharge criteria before the patient transferred from the PACU.

There should be a system for ordering, storing, recording, and auditing of controlled drugs in all postoperative areas in which they are used. ${ }^{19,20}$ In our study, five hospitals (50\%) had such a system as a controlling mechanism.

The postoperative period is known to be painful for the patients unless appropriate pain management is ensured according to a pain score. To identify the pain score, a pain assessment tool is mandatory for all patients. $^{5,10,19,20}$ But in our study, only two (20\%) hospitals used a pain assessment tool for the assessment and management of postoperative pain.

Regarding patient handover, a study done by Weinger et al revealed that a multimodal intervention substantially improved interprofessional PACU handovers, including those by clinicians who had not undergone formal simulation training. ${ }^{32}$ However, in our study we found that there was no training at all in other PACU strategies, and the handover was performed verbally only. The nursing staff in the PACU usually examine the patient chart after the handover staff have left.

Even though a US study demonstrated that checklist implementation while transferring the patient improves the quality of data, there were no formal criteria or checklists for patients being handed over to or discharged from PACUs. This may mean that healthy patients remain in PACUs longer than necessary or patients in the PACU transferred to other wards if there was a shortage of beds. $^{33}$

\section{Limitations}

Since there are no national or local guidelines regarding PACU patient care, we used guidelines and standards from abroad. Variations in patient care in the PACUs among these hospitals is another limitation of this study.

\section{Conclusion}

In the study area, standards, policies and guidelines are not well-prepared and posted so as to be visible to every caregiver. The majority of these hospitals have staff with no special training in the management of possible complications in the PACU.

\section{Recommendations}

We recommend that regional health bureaus allocate budgets to establish well-organized and standardized PACUs in the respective hospitals. Staff assigned to PACUs are recommended to have appropriate training, especially in postoperative patient management. The hospital management and coordinators of PACUs are recommended to facilitate and prepare standards of care. The anesthetists must use appropriate monitoring during transportation to the PACU and stay there until the assigned nurse receives the patient. Verbal and written information transfer for PACU staff regarding the patient's perioperative condition must be implemented. The PACU nurses are recommended to document all the maneuvers, managements, and the findings of the patient until they are transferred from the PACU.

\section{Abbreviations}

AAGBI, Association of Anesthetists of Great Britain and Ireland; AANA, American Association of Nurse Anesthetists; ASA, American Society of Anesthesiologists; CPR, cardiopulmonary resuscitation; OR, operating room; $\mathrm{RR}$, recovery room; PACU, post-anesthesia care unit; USA, United States of America.

\section{Data Sharing Statement}

All necessary data will be provided upon reasonable request.

\section{Funding}

There is no funding to report.

\section{Disclosure}

The authors declare that there is no conflict of interest.

\section{References}

1. Santry HP, Strassels SA, Ingraham AM, et al. Identifying the fundamental structures and processes of care contributing to emergency general surgery quality using a mixed-methods Donabedian approach. BMC Med Res Methodol. 2020;20(1):1-19. doi:10.1186/s12874-020-01096-7 
2. Schittek GA, Schwantzer G, Zoidl P, et al. Adult patients' wellbeing and disturbances during early recovery in the post anaesthesia care unit. A cross-sectional study. Intensive Crit Care Nurs. 2020;61:102912. doi:10.1016/j.iccn.2020.102912

3. Theuerkauf N, Guenther U, Putensen C. Postoperative delirium in the PACU and intensive care unit. Trends Anaesth Crit Care. 2012;2 (4):148-155. doi:10.1016/j.tacc.2012.03.002

4. Marcon E, Dexter F. Impact of surgical sequencing on post anesthesia care unit staffing. Health Care Manag Sci. 2006;9(1):87-98. doi:10.1007/s10729-006-6282-x

5. Luo J, Min S. Postoperative pain management in the postanesthesia care unit: an update. J Pain Res. 2017;10:2687. doi:10.2147/JPR. S142889

6. Macario A, Dexter F. Estimating the duration of a case when the surgeon has not recently scheduled the procedure at the surgical suite. Anesth Analg. 1999;89(5):1241-1245. doi:10.1213/00000539199911000-00030

7. Macario A, Glenn D, Dexter F. What can the postanesthesiacare unit manager do to decrease costs in the postanesthesia care unit? $J$ Perianesth Nurs. 1999;14(5):284-293. doi:10.1016/S10899472(99)80036-7

8. Bell M, Warner J, Cameron A. Patient flow patterns in a recovery room and implications for staffing. J R Soc Med. 1985;78(1):35.

9. Smedley P. BARNA national audit on staffing in the post anaesthetic care unit-results. Br J Anaesth Recovery Nurs. 2012;13(3-4):48-57. doi:10.1017/S1742645612000411

10. Liu H, Yang L, Green M, Kaye AD. Postanesthesia care unit management. In: Operating Room Leadership and Management. 2012:186.

11. Raeder J. Practical recipes from start (preop) to finish (post-discharge). Pract Ambulatory Anesth. 2015;93.

12. Yarborough MJ, Liu H, Bent S. Postanesthesia care unit management. In: Operating Room Leadership and Management. Cambridge University Press; 2009:186-193.

13. Fazio AN, Cottle B. Operating room: survey of recovery rooms shows staffing, utilization patterns. Hosp Top. 1968;46(10):90-95. doi:10.1080/00185868.1968.9952205

14. Mattila AS. The effectiveness of service recovery in a multi-industry setting. J Serv Mark. 2001.

15. Matsusaki T, Sakai T. The role of certified registered nurse anesthetists in the United States. J Anesth. 2011;25(5):734-740. doi:10.1007/ s00540-011-1193-5

16. Woodhead K, Fudge L. Manual of perioperative care: An essential guide. John Willey and Sons; 2012 Jul 23 ;1-10. .

17. Israel JS, DeKornfeld TJ. Recovery Room Care. Year Book Medical Pub; 1987.

18. Moller JT, Wittrup M, Johansen SH. Hypoxemia in the Postanesthesia Care UnitAn Observer Study. Anesthesiology. 1990;73(5):890-895. doi:10.1097/00000542-199011000-00016
19. Kumar G Dr, Walker D Dr, Gooneratne M Dr, Moss C Dr, Stendall DC. Guidelines for the provision of anaesthetic services for postoperative care royal collage of anesthetist. 2019.

20. Anesthetists AAoN. Postanesthesia care standards for the certified registered nurse anesthetist. AANA. 2013.

21. Dexter F, Tinker JH. Analysis of strategies to decrease postanesthesia care unit costs. J Am Soc Anesthesiologists. 1995;82(1):94-101.

22. Epstein RH, Dexter F, Lopez MG, Ehrenfeld JM. Anesthesiologist staffing considerations consequent to the temporal distribution of hypoxemic episodes in the postanesthesia care unit. Anesth Analg. 2014;119(6):1322-1333. doi:10.1213/ANE.0000000000000410

23. Bogod D, Plaat F, Mushambi M, et al. Obstetric population. 2020.

24. Brent R. Patient assessment in recovery. J Perioper Pract. 2010;20 (3):103-107. doi:10.1177/175045891002000303

25. El Tahan MR. How to Organise the PACU? What to Treat in the PACU? Postoperative Care in Thoracic Surgery. Springer; 2017:79-97.

26. Sewell A, Young P. Recovery and post-anaesthetic care. Anaesth Intensive Care Med. 2003;4(10):329-332. doi:10.1383/ anes.4.10.329.27315

27. Marcon E, Kharraja S, Smolski N, Luquet B, Viale JP. Determining the number of beds in the postanesthesia care unit: a computer simulation flow approach. Anesth Analg. 2003;96(5):1415-1423. doi:10.1213/01.ANE.0000056701.08350.B9

28. Whitaker D, Booth H, Clyburn P, et al; Party: MotW. Immediate postanaesthesia recovery 2013: Association of Anaesthetists of Great Britain and Ireland. Anaesthesia. 2013;68(3):288-297. doi:10.1111/ anae. 12146

29. Chung F. Discharge criteria-a new trend. Can J Anaesth. 1995;42 (11):1056-1058. doi:10.1007/BF03011083

30. Phillips NM, Street M, Kent B, Haesler E, Cadeddu M. Post-anaesthetic discharge scoring criteria: key findings from a systematic review. Int $J$ Evid Based Healthcare. 2013;11(4):275-284. doi:10.1111/1744-1609.12044

31. Cowie B, Corcoran P. Postanesthesia care unit discharge delay for nonclinical reasons. J Perianesth Nurs. 2012;27(6):393-398. doi:10.1016/j.jopan.2012.05.013

32. Weinger MB, Slagle JM, Kuntz AH, et al. A multimodal intervention improves postanesthesia care unit handovers. Anesth Analg. 2015;121 (4):957-971. doi:10.1213/ANE.0000000000000670

33. Park LS, Yang G, Tan KS, et al. Does checklist implementation improve quantity of data transfer: an observation in postanesthesia care unit (PACU). Open J Anesthesiol. 2017;7(4):69. doi:10.4236/ ojanes.2017.74007
Drug, Healthcare and Patient Safety

\section{Publish your work in this journal}

Drug, Healthcare and Patient Safety is an international, peer-reviewed open-access journal exploring patient safety issues in the healthcare continuum from diagnostic and screening interventions through to treatment, drug therapy and surgery. The journal is characterized by the rapid reporting of reviews, original research, clinical, epidemiological and post-marketing surveillance studies, risk management, health literacy and educational programs across all areas of healthcare delivery. The manuscript management system is completely online and includes a very quick and fair peer-review system. Visit http://www.dovepress.com/testimonials.php to read real quotes from published authors. 